\title{
Energy and Nutrient Recovery from Cattle Feedlots
}

\author{
Roger A. Eigenberg, ${ }^{1}$ Bryan L. Woodbury, ${ }^{1}$ Brent W. Auvermann, ${ }^{2}$ \\ David B. Parker, ${ }^{1}$ and Mindy J. Spiehs ${ }^{1}$ \\ ${ }^{1}$ U.S. Meat Animal Research Center, P.O. Box 133, Clay Center, NE 68933, USA \\ ${ }^{2}$ Texas AgriLife Research, 6500 Amarillo Boulevard W, Amarillo, TX 79106, USA \\ Correspondence should be addressed to Mindy J. Spiehs, mindy.spiehs@ars.usda.gov
}

Received 25 August 2011; Accepted 3 October 2011

Academic Editor: E. R. Bandala

Copyright ( 2012 Roger A. Eigenberg et al. This is an open access article distributed under the Creative Commons Attribution License, which permits unrestricted use, distribution, and reproduction in any medium, provided the original work is properly cited.

\begin{abstract}
Selective harvesting of manure can benefit cattle producers by creating a product of value. A tool that identifies locations of manure accumulation has been developed using a subsurface sensor (Dualem-1S, Milton, ON) and software designed for salt mapping (ESAP, Riverside, CA). The combination allowed the development of models to estimate higher heating value (HHV) of feedlot manure across a feedlot pen. Soil sample data from cattle feedlots in Texas and Nebraska were analyzed for volatile solids (VSs) then combined with the Dualem-1S apparent soil conductivity $\left(\mathrm{EC}_{\mathrm{a}}\right)$ data to produce models having correlations between associated $\mathrm{EC}_{\mathrm{a}}$ values and VS $\left(r^{2}=0.869, \mathrm{VS}\right)$. A corresponding model is under development to estimate the moisture content of the collectable solids. The combined models allow real-time spatial estimates of HHV within a feedlot pen. These methods will allow direct harvesting of VS for use as a recoverable energy source through direct combustion or cocombustion.
\end{abstract}

\section{Introduction}

A major focus of feedlot nutrient management is the feedlot surface. Assessing and removing nutrient concentrations directly from the feedlot surface presents one option for minimizing environmental impact. Remedial steps taken early in the waste management system increase the effectiveness of treatment "downstream" in the process. Precision harvesting promises reduction in greenhouse gas production, odor production, nutrient loading in liquid runoff, and reduction in subsequent nutrient leaching. Furthermore, loading and hauling of feedlot manures can become a significant fixed cost [1]; minimizing the number of loads and maximizing the nutrient concentrations lead to lower nutrient transport costs.

A challenge facing manure managers is to assess the value of the raw product as manure often has had a negative value associated with it. Manure has been considered a liability and something that had to be disposed of or stored. Modern geophysical methods [2] offer the potential to identify locations with manure buildup such that the quality of the harvested material can be substantially enhanced. The identified concentrated manure may take on value that would not be possible otherwise.
Methods of identifying manure buildup must rely on characteristics that are specific to the manure. Beef cattle manure contains nitrogen, phosphorus, potassium, calcium, magnesium, sulfur, sodium, chloride, iron, and other trace minerals which result in average $\mathrm{EC}$ values in the range of $3.7 \mathrm{dS} / \mathrm{m}$ [3]. Soil may have average EC values of 0.1 to $1.1 \mathrm{dS} / \mathrm{m}$, ranging from nonsaline/coarse soil to very saline clay [4]. Accumulation of beef manures on feedlot surfaces has been shown to elevate soil EC, and electromagnetic induction (EMI) measurements of electrical conductivity have demonstrated sensitivity to areas of high nutrient levels [5].

\section{Objective}

The objective of this work was to demonstrate methods to locate areas of manure buildup deposited on feedlot pen surfaces and to quantify concentrations of nutrients or volatile solids (contained in the manure).

\section{Methods}

Apparent soil electrical conductivity $\left(\mathrm{EC}_{\mathrm{a}}\right)$ measurements were collected using a Dualem-1S (Dualem Inc., Milton, ON, 


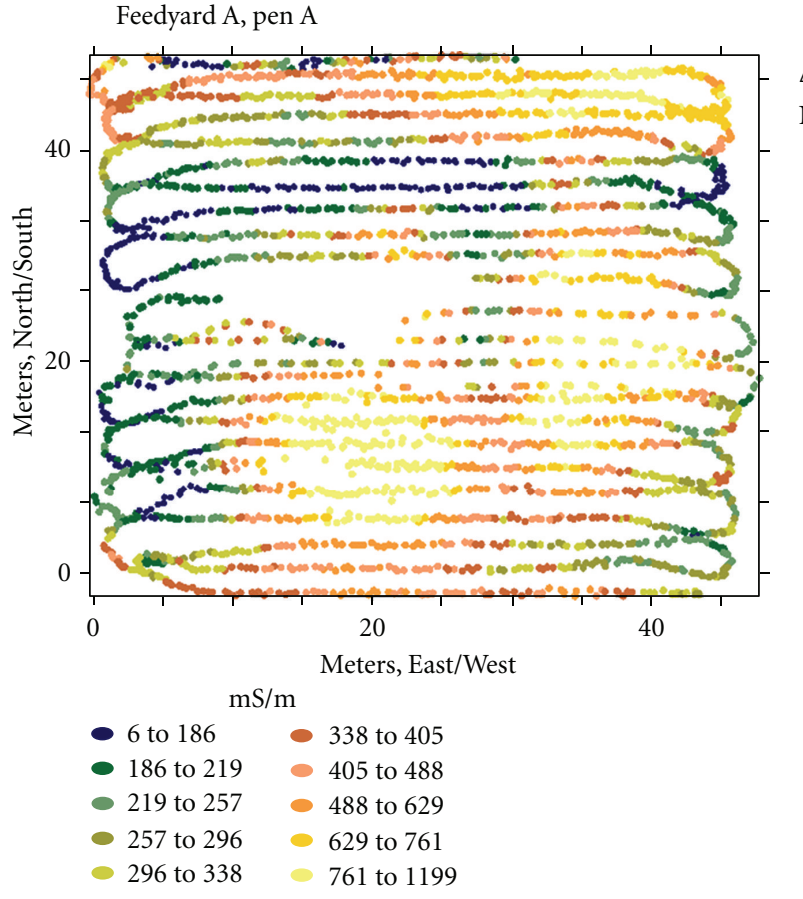

(a)

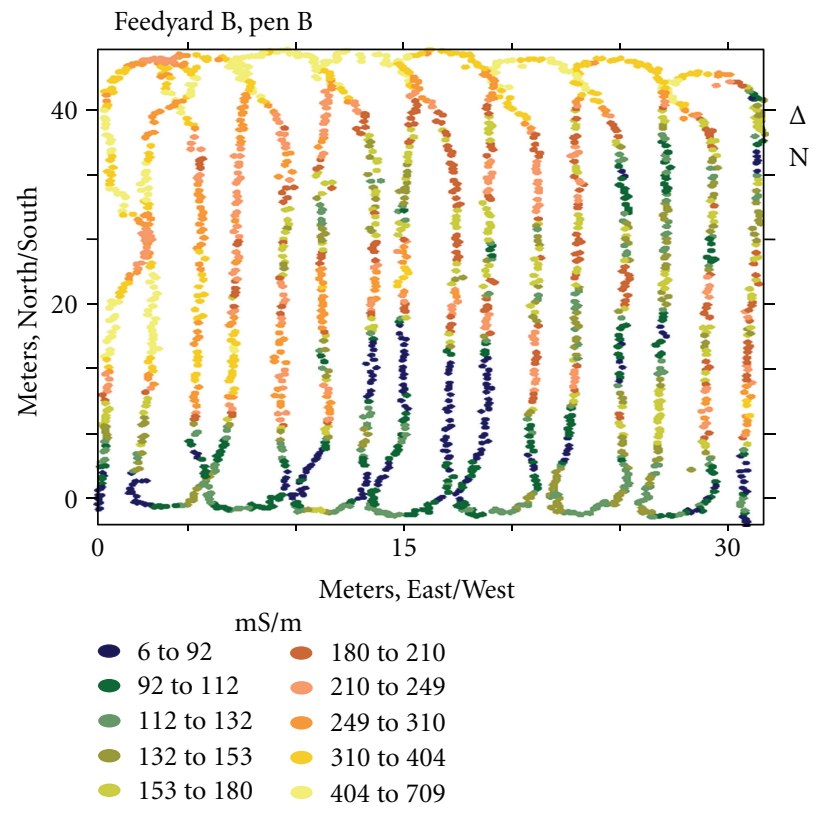

(b)

FIGURE 1: Electromagnetic surveys of two feedlot pens from the Panhandle of Texas (March, 2009). Light-colored data points represent high soil conductivity; darker colors represent low conductivities.

Canada). The Dualem-1S operates in the horizontal coplanar (HCP) and perpendicular (PRP) geometry simultaneously. The Dualem-1S was mounted on a non-metallic sled and pulled by an all-terrain vehicle at about $2-4 \mathrm{~km} / \mathrm{hr}$, with passes made every $1.5 \mathrm{~m}$. Apparent soil electrical conductivity was recorded and stored at a rate of 4 readings second $^{-1}$, with corresponding GPS coordinates provided by a Trimble EZ-Guide GPS/Guidance system (Trimble Navigation Limited, Sunnyvale, CA).

The surveys to develop the calibration equations were conducted during October 2004 and June 2005 on open cattle feedlot pens in South Central Nebraska and in the Panhandle of Texas. Soil sample sites were chosen based on $\mathrm{EC}_{\mathrm{a}}$ maps with sites selected in high, middle, and low $\mathrm{EC}_{\mathrm{a}}$ values. The soil samples were collected to a depth of 3$4 \mathrm{~cm}$ and analyzed for total nitrogen (TN), total phosphorus (TP), and volatile solids (VSs). The analysis for TN [6] and TP $\left(\mathrm{HClO}_{4}\right.$ digestion, [7] $)$ were done by a commercial laboratory (Ward Laboratories, Kearney, NE). Volatile solid analyse were done in house at the U.S. Meat Animal Research Center were determined by loss of ignition, and were based on mass lost after combustion at a temperature of $550^{\circ} \mathrm{C}$ for approximately 15 hours.

Fifty-two sites were sampled; soil constituents including TN, TP, and VS were determined from each site. The associated $\mathrm{EC}_{\mathrm{a}}$ values from each site were correlated to the soil constituent resulting in the following sigmoidal equations as developed using SigmaPlot:

$$
\mathrm{TN}=\frac{22816.9}{\left(1+\exp \left(-\left(\mathrm{EC}_{\mathrm{a}}-146.5\right) / 21.6\right)\right)},
$$

where $\mathrm{TN}=$ total nitrogen, $\mathrm{ppm}, \mathrm{EC}_{\mathrm{a}}=$ apparent soil conductivity, $\mathrm{mS} / \mathrm{m}$,

$$
\mathrm{TP}=\frac{8628.5}{\left(1+\exp \left(-\left(\mathrm{EC}_{\mathrm{a}}-152.4\right) / 30.0\right)\right)}
$$

where $\mathrm{TP}=$ total phosphorus, $\mathrm{ppm}, \mathrm{EC}_{\mathrm{a}}=$ apparent soil conductivity, $\mathrm{mS} / \mathrm{m}$,

$$
\mathrm{VS}=\frac{.598}{\left(1+\exp \left(-\left(\mathrm{EC}_{\mathrm{a}}-167.5\right) / 36.8\right)\right)}
$$

where VS = volatile solids, fraction, $\mathrm{EC}_{\mathrm{a}}=$ apparent soil conductivity, $\mathrm{mS} / \mathrm{m}$.

The equations for TN, TP, and VS explained over $85 \%$ of the variability in the data with $R^{2}$ values of $0.874,0.868$, and 0.869 , respectively.

\section{Results and Discussion}

Surveys (March, 2009) were made of pens in the Panhandle of Texas using surveying methods as described above. Two pens were selected (Feedlot A, Pen A (approximately $45 \times$ $45 \mathrm{~m}$ ) and Feedlot B, Pen B (approximately $31 \times 43 \mathrm{~m}$ )) for comparison to demonstrate the economic value of manure based on predictive models and subsequent pen surveys (note: management details for these two pens were not available). The $\mathrm{EC}_{\mathrm{a}}$ maps of the two recent surveys are shown in Figure 1. 


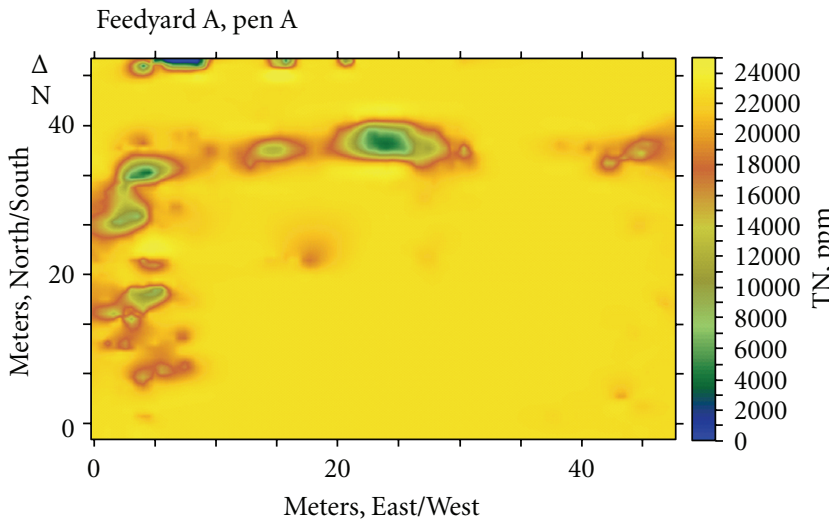

(a)

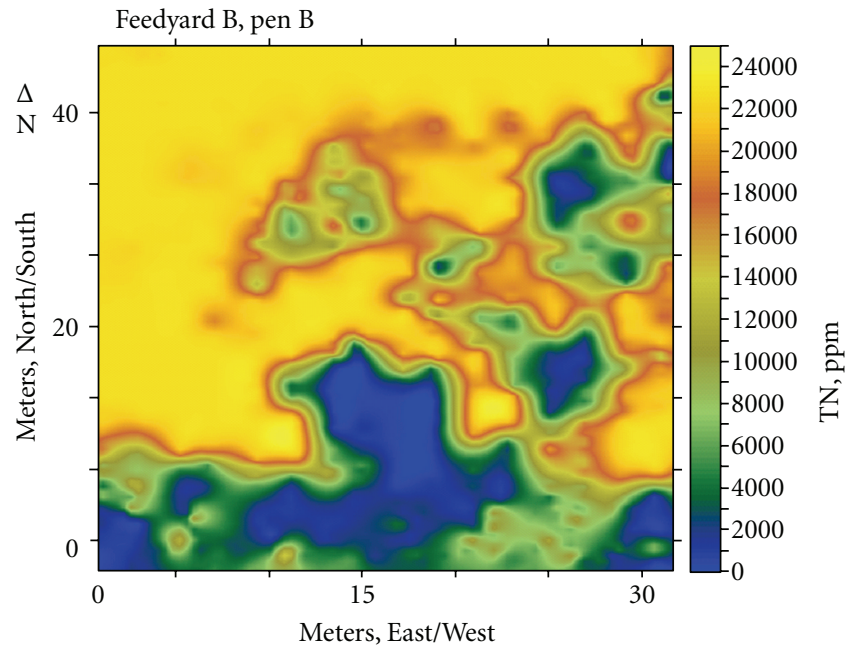

(b)

FIGURE 2: Gridded map of estimated TN based on predictive equations. Light colors represent high predicted concentrations of TN; darker areas indicate low concentrations. The two pens demonstrate the high variability that occurs among pens.

TABLE 1: Value of nutrients based on prediction maps. Harvesting whole pen is compared to selective harvesting with a threshold set at $1.7 \%$ for TN.

\begin{tabular}{|c|c|c|c|c|}
\hline & Feedyard A, Pen A & Feedyard B, Pen B & $\begin{array}{c}\text { Feedyard A, Pen A } \\
\text { TN }>1.7 \%\end{array}$ & $\begin{array}{c}\text { Feedyard B, Pen B } \\
\text { TN }>1.7 \%\end{array}$ \\
\hline Average TP, ppm & 8025 & 5387 & 8306 & 7943 \\
\hline Average TN, ppm & 21724 & 14712 & 22420 & 21891 \\
\hline Mass, TP, kg & 2193 & 969 & 2126 & 772 \\
\hline Mass, TN, kg & 5939 & 2647 & 5738 & 2128 \\
\hline Total harvested mass, $\mathrm{kg}$ & 273,000 & 180,000 & 256,000 & 97,000 \\
\hline Value $/ \mathrm{m}^{3}, \mathrm{TP}, \$ / \mathrm{m}^{3}$ & 1.97 & 1.32 & 2.04 & 1.95 \\
\hline Value $/ \mathrm{m}^{3}, \mathrm{TN}, \$ / \mathrm{m}^{3}$ & 3.76 & 2.54 & 3.88 & 3.79 \\
\hline$\$ / \mathrm{m}^{3}$, total & 5.73 & 3.86 & 5.92 & 5.74 \\
\hline
\end{tabular}

Estimates of the value of the nutrients in the manure were made based on the following assumptions:

(i) soil density $=0.9 \mathrm{gm} / \mathrm{cm}^{3}$,

(ii) surface material collected to $15 \mathrm{~cm}$,

(iii) $22 \%$ of TP available in first year,

(iv) $35 \%$ of $\mathrm{TN}$ available in first year,

(v) phosphate $(45 \%)$ fertilizer valued at $\$ 510 /$ ton (April 2010 price, http://www.ers.usda.gov/data/ fertilizeruse/),

(vi) anhydrous ammonia valued at \$425/ton (April 2010 price, http://www.ers.usda.gov/data/fertilizeruse/).

Equations (1) and (2) relate $\mathrm{EC}_{\mathrm{a}}$ to $\mathrm{TN}$ and TP. Each measured value of $\mathrm{EC}_{\mathrm{a}}$ on the pens (Figure 1) was replaced with a predicted value of either TN or TP. The predicted values of TN or TP were then used to generate a new figure showing estimated TN or TP across the pen surface. Surfer was then applied to create gridded maps of the predicted values for TN and TP. The gridded maps of the estimated $\mathrm{TN}$ are shown in Figure 2.

Table 1 summarizes the nutrient quantities for pens from both Feedyards A and B. Two scenarios were compared. The first scenario was harvesting of the entire pen to a depth of $15 \mathrm{~cm}$. If the values of TP and TN are independent and additive, then the total value of the harvested manure can be assigned for the entire pen. Values of a cubic meter of pen material were compared for each pen. Additionally, a comparison was made for a product that was selectively harvested for areas that exceed a threshold of $\mathrm{TN}>1.7 \%$ ( $1.7 \%$ chosen to illustrate the effect of selective cleaning). Selective harvesting of Pen A resulted in the value of a cubic meter increasing from an estimated $\$ 5.73$ to $\$ 5.92$, an increase of about 3\%. Selective harvesting of Pen B, with less concentrated manure distribution, revealed a change in value of a cubic meter from $\$ 3.86$ to $\$ 5.74$; an increased value of about $48 \%$ while reducing the mass to be trucked by a factor of about 1.8 .

An alternative to nutrient recovery and utilization for cropland is harvesting feedlot manure as an energy source. 


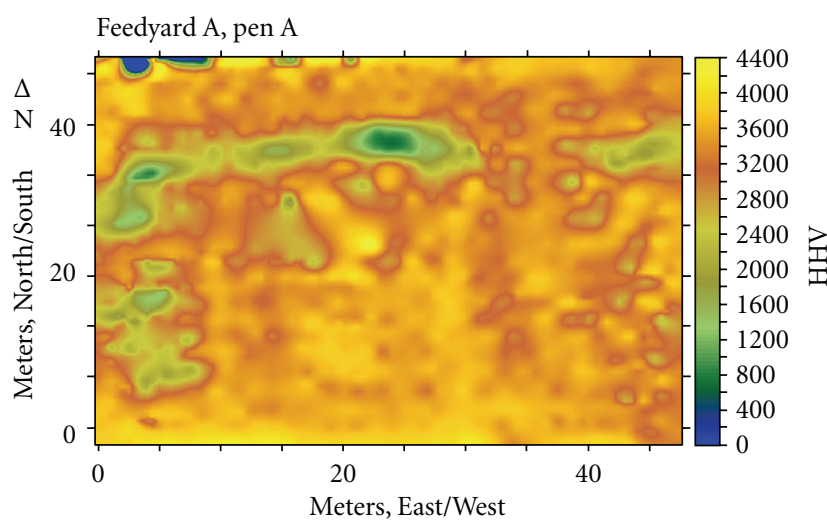

(a)

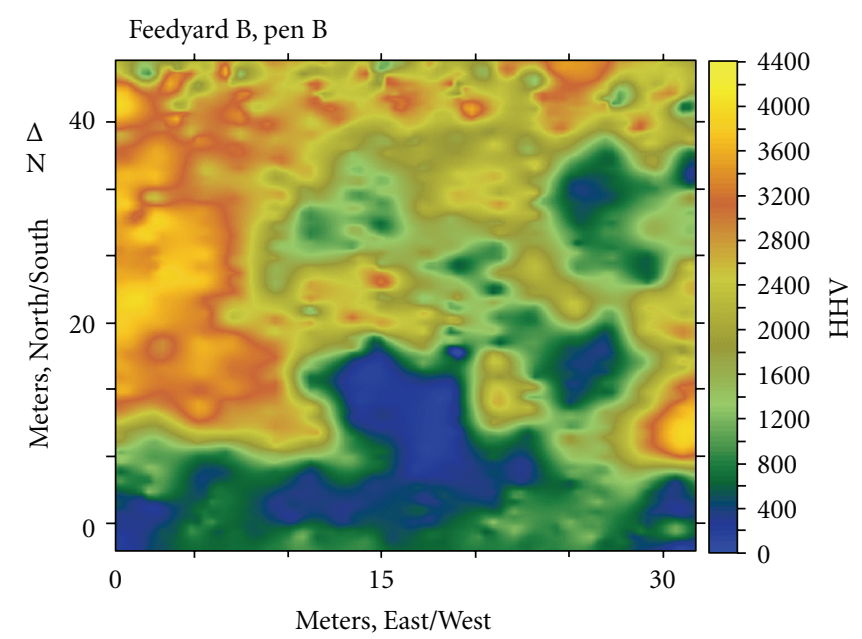

(b)

FIgURE 3: Estimated energy for feedlot pens A and B. Light colors represent high predicted energy concentrations; darker areas indicate low-energy recovery potential.

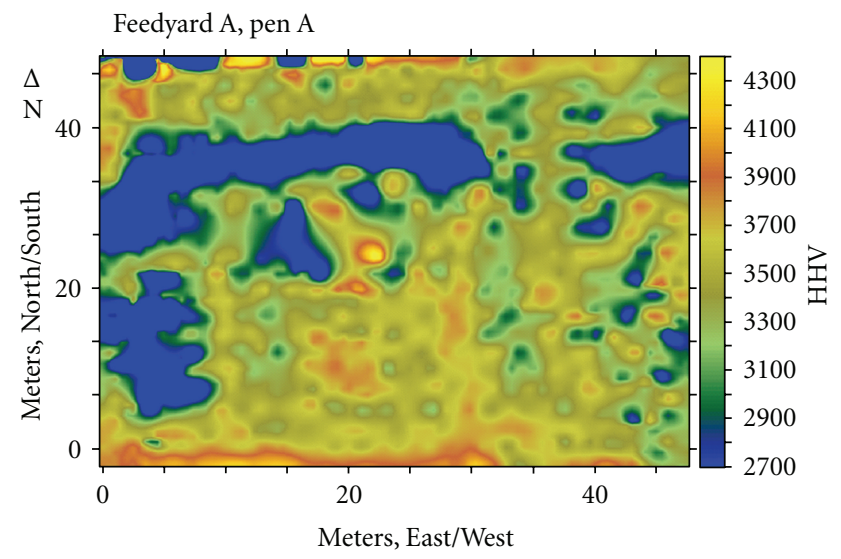

(a)

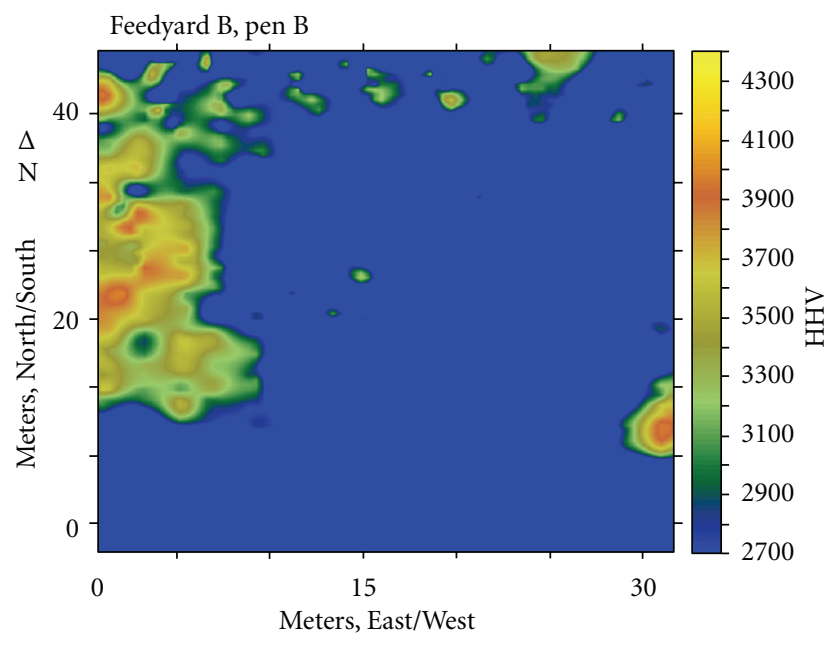

(b)

FIGURE 4: Feedyard pens with energy threshold at 2700 BTU/lb. Setting the threshold at 2700 BTU/lb vividly demonstrates the differences among pens. Selective harvesting of only the areas of high concentration would assure a better product for direct combustion.

The work in [8] has demonstrated the potential for use of feedyard manure for direct combustion. A relationship was developed between VS and moisture content (MC) as shown:

$$
\mathrm{HHV}=0.85 * \mathrm{VS} *(100-\mathrm{MC}),
$$

where HHV is the higher heating value in BTU/lb, VS is the volatile solids content as $\mathrm{a} \%$, and $\mathrm{MC}$ is the moisture content as $\mathrm{a} \%$.

Equation (3) served as a predictor of VS based on soil conductivity. Each $\mathrm{EC}_{\mathrm{a}}$ value of Figure 1 was replaced by a predicted VS value based on (3). Equation (4) was then applied to the VS values to generate estimated HHV values. A constant moisture content was assumed for illustration of the value of energy recovery. Current work on the use of the $\mathrm{EC}_{\mathrm{a}}$ signal to predict MC has shown promise but is not mature and will not be discussed here.
Energy prediction maps are shown in Figure 3.

The calculations for value of harvested manure as an energy resource were based on the following assumptions:

(i) soil density $=0.9 \mathrm{gm} / \mathrm{cm}^{3}$,

(ii) surface material collected to $15 \mathrm{~cm}$,

(iii) powder River coal is valued at $\$ 12.40 /$ ton (energy content at 8,800 BTU/lb, April 2010 price),

(iv) natural gas is valued at $\$ 0.617 /$ therm $(100,000 \mathrm{BTU} /$ therm, January 2010 price).

The generalized predictive (3) was used to predict both VS at each point on the survey grid. Estimates of pen totals for HHV were estimated based on a constant MC and were summed over the entire survey. Gridded maps (using Sufer) of the estimated HHV are shown in Figure 4. 
TABLE 2: Value of energy based on prediction maps. Harvesting whole pen is compared to selective harvesting with a threshold set at $\mathrm{HHV}>2700$.

\begin{tabular}{lcccc}
\hline & Feedyard A, Pen A & Feedyard B, Pen B & $\begin{array}{c}\text { Feedyard A, Pen A } \\
\text { HHV }>2700\end{array}$ & $\begin{array}{c}\text { Feedyard B, Pen B } \\
\text { HHV }>2700\end{array}$ \\
\hline Average Energy, BTU/lb & 3224 & 1771 & 3450 & 3228 \\
Area Harvested, \% & 100 & 100 & 85 & 24 \\
Harvested mass, $\mathrm{kg}$ & 273,000 & 180,000 & 233,000 & 43,000 \\
Value $/ \mathrm{m}^{3}$, energy, $\$ / \mathrm{m}^{3}$ (coal) & 21.87 & 12.01 & 23.40 & 21.90 \\
Value $/ \mathrm{m}^{3}$, energy, $\$ / \mathrm{m}^{3}$ (gas) & 39.48 & 21.69 & 42.25 & 39.53 \\
\hline
\end{tabular}

Table 2 summarizes the HHV quantities for pens in Feedyards A and B. Two scenarios were compared, the first was harvesting of the entire pen to a depth of $15 \mathrm{~cm}$. Values of a cubic meter of pen material were compared for each pen. Additionally, a comparison was made for a product that was selectively harvested (also to a depth of $15 \mathrm{~cm}$ ) for areas that exceeded a threshold of HHV > 2700 BTU/lb. Selective harvesting increased the value (based on replacement of coal) of Pen A from $\$ 21.87$ to $\$ 23.40$, an increase of about $7 \%$. Pen $\mathrm{B}$, with less concentrated manure distribution, revealed a change in value of a cubic meter from about $\$ 12$ to $\$ 22$; selective harvesting this pen resulted in an increase of about $82 \%$ in value while reducing the mass to be trucked by a factor of about 4 . In reality, the value change is much greater since the manure only has value as a direct combustion material if the $\mathrm{HHV}$ exceeds $2700 \mathrm{BTU} / \mathrm{lb}$; the value change in reality was from $\$ 0$ to $\$ 22$ per cubic meter (as estimated for the replacement of coal).

\section{Conclusion}

Unmanaged manure accumulation on feedlot pen surfaces has the potential to negatively impact the environment through runoff, leaching, and gaseous emissions. Selective harvesting of biosolids can benefit the cattle producer by creating a product of significant value. A tool was described that generated maps to guide the harvesting of manure to maximize the nutrient and/or energy recovery. A hypothetical harvester that collected manure to a depth of $15 \mathrm{~cm}$ from two Texas feedlot pens demonstrated increased value of the harvested manure for nutrients up to nearly $50 \%$. When the manure is suitably harvested for energy recovery, the value of the manure is nearly quadruple (based on replacement of coal) the value for nutrient recovery.

\section{Disclosure}

USDA is an equal opportunity provider and employer. The mention of trade names of commercial products in this article is solely for the purpose of providing specific information and does not imply recommendation or endorsement by the USDA.

\section{References}

[1] Tetra Tech, Inc, "EPA regional priority AFO science question synthesis document-manure management," Prepared for: Office of Science Policy, Office of Research and Development, United States Environmental Protection Agency, Washington DC, USA, 2004.

[2] B. L. Woodbury, S. M. Lesch, R. A. Eigenberg, D. N. Miller, and M. J. Spiehs, "Electromagnetic induction sensor data to identify areas of manure accumulation on a feedlot surface," Soil Science Society of America Journal, vol. 73, no. 6, pp. 2068-2077, 2009.

[3] C. B. Gilbertson, J. R. Ellis, and J. A. Nienaber, "Properties of manure accumulations from Midwest beef cattle feedlots," Transactions of the American Society of Agricultural Engineers, vol. 18, no. 2, pp. 327-330, 1975.

[4] J. L. Smith and J. W. Doran, "Measurement and use of pH and electrical conductivity for soil quality analysis," in Methods for Assessing Soil Quality, J. W. Doran and A. J. Jones, Eds., SSSA Spec Publ. 49, pp. 169-185, SSSA, Madison, Wis, USA, 1996.

[5] R. A. Eigenberg, R. L. Korthals, and J. A. Nienaber, Electromagnetic Survey Methods Applied to Agricultural Waste Sites, ASAE Paper No. 963014, ASAE, St. Joseph, Mich, USA, 1996.

[6] J. M. Bremner, "Nitrogen-Total," in Methods of Soil Analysis. Part 3, D. L. Sparks, Ed., SSSA Book Ser. 5, pp. 1085-1121, SSSA, Madison, Wis, USA, 1996.

[7] S. Kuo, "Phosphorus," in Methods of Soil Analysis. Part 3, D. L. Sparks, Ed., SSSA book Ser. 5, pp. 869-919, SSSA, Madison, Wis, USA, 1996.

[8] S. Priyadarsan, K. Annamalai, J. M. Sweeten, M. T. Holtzapple, and S. Mukhtar, Waste to Energy: Fixed Bed Gasification of Feedlot and Chicken Litter Biomass, ASABE Paper No. 034135, ASABE, St. Joseph, Mich, USA, 2003. 

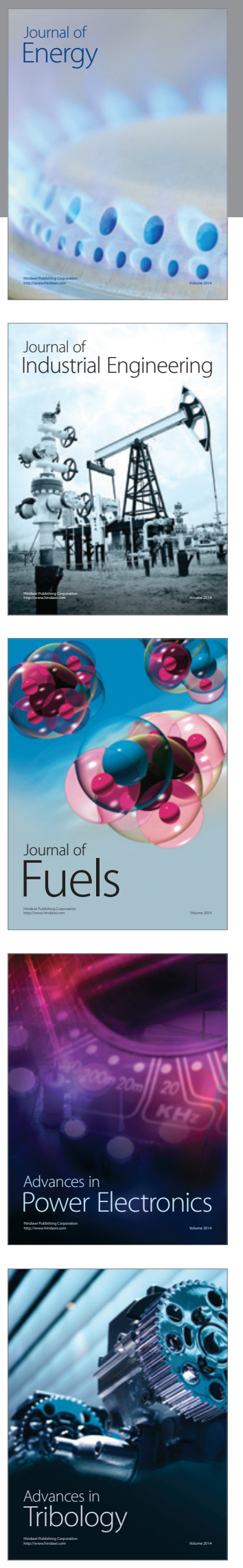
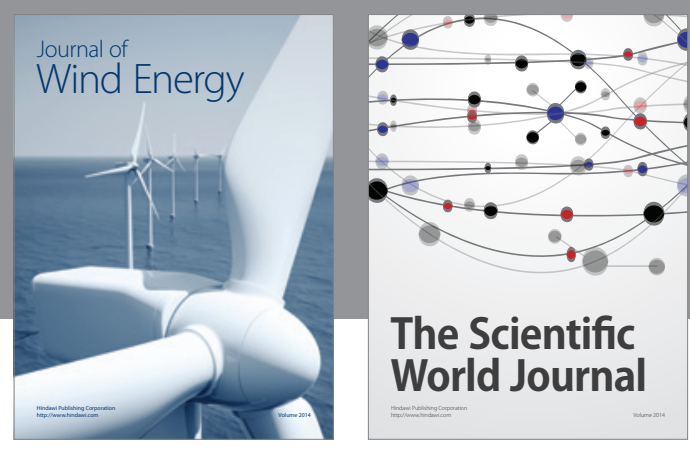

The Scientific World Journal

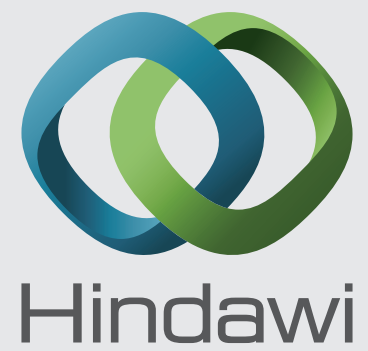

Submit your manuscripts at http://www.hindawi.com
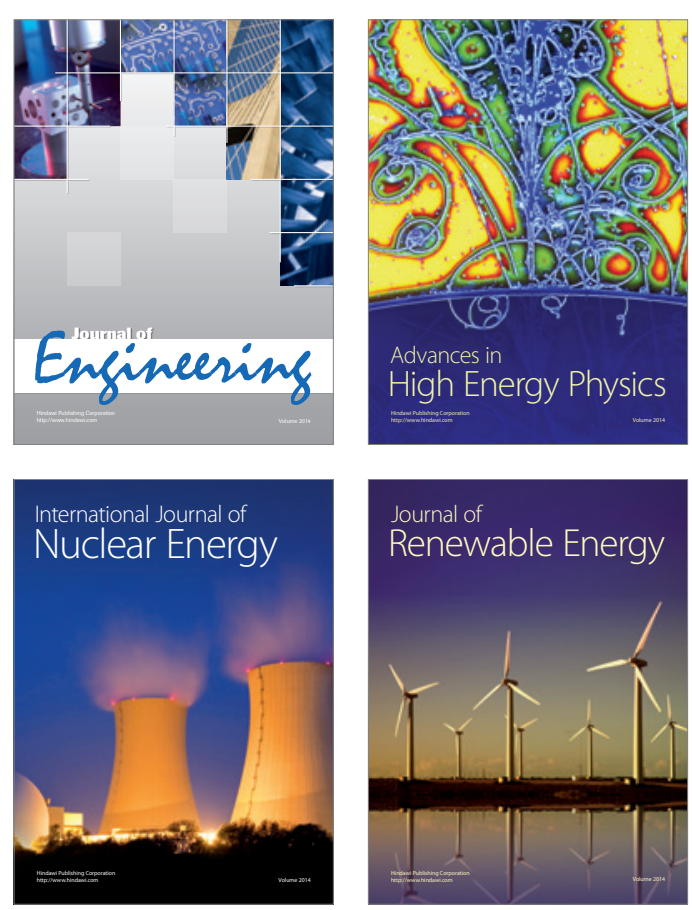

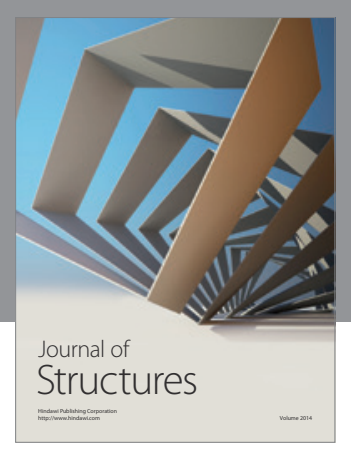

Rotating
Mechinery
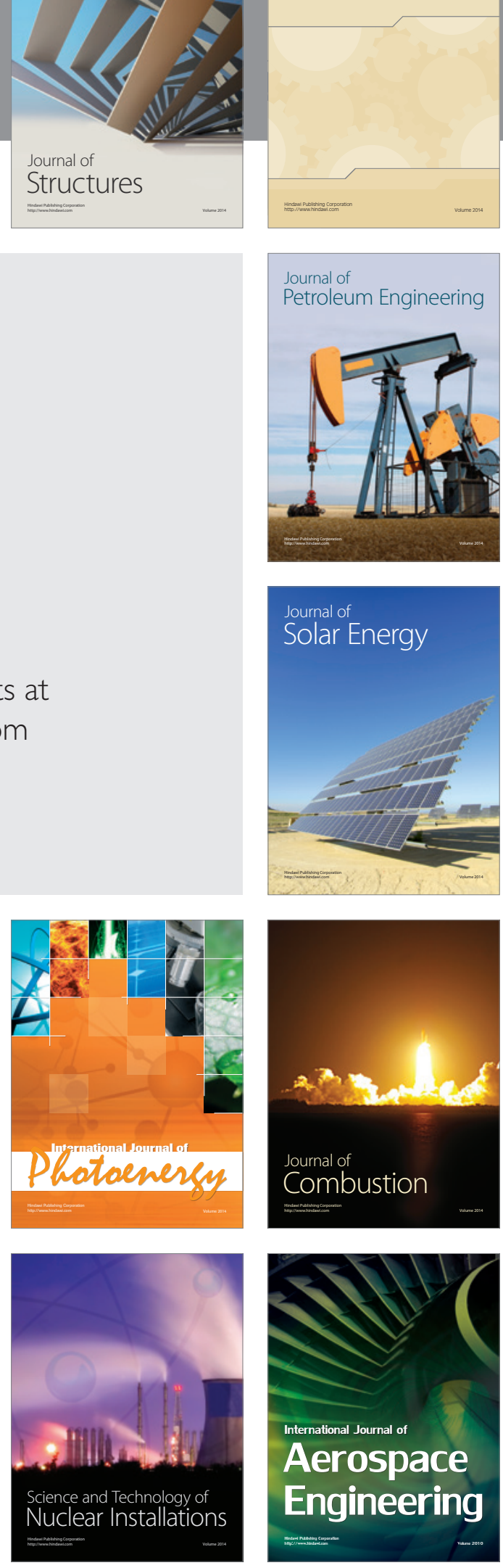